\title{
EFEITO DO ESTIOLAMENTO PARCIAL E DO ÁCIDO INDOLBUTÍRICO (IBA) NO ENRAIZAMENTO DE ESTACAS DE RAMOS DE GOIABEIRA SERRANA
}

(Feijoa sellowiana, Berg) ${ }^{1}$

\author{
S.L.B. FIGUEIREDO²; E. KERSTEN'; M.W. SCHUCH ${ }^{2}$ \\ ${ }^{2}$ Faculdade de Agronomia "Eliseu Maciel"/UFPEL, C.P. 354, CEP: 96010-900-Pelotas, RS
}

\begin{abstract}
RSSUMO: Com o objetivo de verificar o efeito do estiolamento parcial dos ramos e do ácido indolbutírico (IBA), no enraizamento de estacas de Feijoa sellowiana, conduziu-se este trabalho de enraizamento em trés épocas de estiolamento, utilizando-se câmara de nebulização. Antes das estacas serem retiradas efetuou-se o estiolamento dos ramos de diversas plantas, com uniformidade de tamanho e idade. Foram utilizadas estacas de ramos em três intervalos de estiolamento (zero, 40 e 60 dias), tratadas com Zero; 5000; 7000; 9000 e 11000 ppm de IBA, na formulaçåo de po. Foi avaliado o número de estacas enraizadas, determinando-se a percentagem de enraizamento. Os resultados mostraram que estiolamento parcial foi efetivo para o enraizamento, sendo que 0 melhor intervalo foi variável conforme a época de estiolamento dos ramos e o IBA teve efeito negativo sobre o enraizamento. Descriteres: estiolamento, ácido indolbutírico, estacas, enraizamento, Feijoa sellowiana
\end{abstract}

\section{EFECTS OF BLANCHING AND OF INDOLBUTYRIC ACID (IBA) IN THE ROOTING OF Feijon sellowiana, Berg. CUTTINGS}

SUMMARY: With the aim of verifying branching and indolbutyric acid (IBA) effects on the rootting of cuttings of feijoa, this work was carried out considering three different dates of blanching, in greenhouse. The branching of various plants with uniform size and age was performed prior to branch trimming. Branch cuttings obtained at three blanching times (Zero, 40 and 60 days); treated with Zero; 5000; 7000; 9000 and 11000 ppm of power IBA, were used. The number of rooted cuttings was evaluated in order to calculate percent rooting. The results showed that the blanching was effective in rooting and the best time was variable according to the date of branch blanching; the IBA showed negative effect on rooting.

Key Wonds: blanching, indolbutiric acid, cuttings, rooting, Feljoa sellowiana

\section{INTRODUÇÃO}

A goiabeira serrana (Feijoa sellowiana Berg), é uma espécie nativa do Sul do Brasil, Argentina, Uruguai e Paraguai, com grande variabilidade do tamanho da planta, forma $e$ tamanho dos frutos.

Para CACIOPPO (1988), a feijoa demonstra que pode vegetar satisfatoriamente apresentando produtividade mesmo quando seu sistema radicular não proceda de sementes.

A feijoa é uma espécie que pode ser propagada através de sementes ou por estaquia, enxertia, mergulhia e alporquia (MATTOS, 1986; CACIOPPO, 1988; FACHINELLO et al., 1992).
Para a iniciação de raízes adventícias em estacas, certos níveis de substâncias vegetais de crescimento são mais favoráveis do que outros. Dentre os grupos de tais substâncias encontram-se as auxinas, citocininas, giberelinas, ácido abscísico e o etileno. Destas, as auxinas são as de maior interesse para a formação de estacas (HARTMANN \& KESTER, 1990).

A descoberta de que as auxinas estimulam a divisão celular $e$, conseqüentemente, a iniciação de raízes, levou pesquisadores e viveiristas a empregá-las em estacas, visando estimular a formação de raízes (WEAVER, 1989).

Segundo HARTMAN \& KESTER (1990), é provável que para estabelecer condições

\footnotetext{
${ }^{1}$ Parte da Dissertação de Mestrado do primeiro Autor - FAEM/UFPEL
} 
que favoreçam a iniciação de raízes existam interações entre certos fatores fixos situados dentro da célula, talvez certas enzimas, nutrientes facilmente translocáveis e fatores endógenos do enraizamento.

Sabe-se que a técnica do estiolamento é conhecida, há muito tempo, como eficaz para aumentar a formação de raízes adventícias em tecidos de ramos. Em 1864, Sachs demonstrou-a experimentalmente (WEAVER, 1976).

Numerosas hipóteses têm sido estabelecidas para explicar o mecanismo de ação das auxinas no enraizamento, sendo que relações com ácidos nucléicos e proteínas, modificações na parede celular, secreção de íons hidrogênio e estimulação na atividade enzimática, correspondem aos principais enfoques aventados (CASTRO, 1979). A síntese de ácidos nucléicos e de proteínas, sob efeito de auxínas, mostra-se importante para o mecanismo de expansão da parede celular.

PILERI (1989), menciona que na Nova Zelândia a propagação da feijoa por estacas é preferida aquela por enxertia, pelos seguintes motivos: a) ao semear-se a semente de feijoa, o porta-enxerto apresenta maior tendência a produzir rebentos em relação às estacas enraizadas; b) a planta enxertada, em condições de ventania. facilmente se quebra no ponto de enxertia.

O enraizamento de estacas de feijoa começa com 3 a 3,5 meses após o plantio (GORGOSHIDZE, 1971; PIRCHALAJSVILI, 1970; KULIEV \& BABAEV, 1983; BABAEV \& ABBASOVA, 1985). Porém, para CACIOPPO (1988) e PILERI (1989), o intervalo de tempo para o enraizamento varia de oito a doze semanas.

Segundo GORGOSHIDZE (1971), ramos oriundos de plantas diferentes, apresentam diferenças significativas no enraizamento, assim como a posição da estaca em relação ao ramo. $O$ mesmo autor, ainda verificou que o estiolamento dos ramos com fita isolante, aumentou $5 \%$ o percentual de enraizamento em relação ao controle.

MEREDITH et al. (1970), em trabalho com ácido indolacético (IAA) e cinetina, constataram que o IAA pode melhorar o enraizamento de estacas de feijoa, por estimulação, alongamento e desenvolvimento de raízes iniciais pré-formadas; a cinetina pode ter estimulado a formação de raízes.

DOUD \& CARLSON (1977), em estudos com diferentes porta-enxertos de macieira (Malus spp) e estiolamento dos ramos, observaram que, quando em nebulização intermitente, as esta- cas de ramos estiolados enraizaram rapidamente, $\mathrm{e}$ as não estioladas enraizaram deficientemente.

DUARTE (1991), em trabalho com enraizamento de estacas semilenhosas de feijoa, coletadas em duas épocas e submetidas a diferentes concentrações de IBA, observou que, após 67 dias no substrato de areia, o tratamento com $5000 \mathrm{ppm}$ de IBA foi o que proporcionou maior número de estacas enraizadas, atingindo $31,66 \% \mathrm{em}$ março/maio e $21,66 \%$ em dezembro/fevereiro.

$O$ objetivo do presente trabalho foi avaliar o enraizamento de estacas de F.sellowiana, mediante a utilizaçåo do estiolamento parcial dos ramos e o uso de ácido indolbutírico (IBA).

\section{MATERIAL E MÉTODOS}

Este trabalho foi realizado em câmara de nebulização do Departamento de Fitotecnia, da Faculdade de Agronomia "Eliseu Maciel"/UFPEL, RS. Antes da colocação das estacas na câmara de nebulização, foi realizado estiolamento parcial dos ramos de feijoa, em três épocas: Época 1 (maio/ 91); Época 2 (novembro/91) e Época 3 (fevereiro/ 92). Nas três épocas, foram estiolados, parcialmente, ramos provenientes da porção basal e mediana de várias plantas em semelhantes condições de idade e tamanho.

Os "seedlings" utilizados tinham 30,36 e 40 meses de idade, respectivamente, para as épocas 1,2 e 3.

O estiolamento parcial foi feito com fita preta de polietileno, no $7^{\circ}$ par de folhas $\left(7^{\circ}\right.$ nó) contados do ápice para a base dos ramos, abrangendo $2 \mathrm{~cm}$ abaixo e acima do nó. Os ramos permaneceram nessas condições durante 40 e 60 dias.

O preparo das estacas foi feito cortando-se os ramos abaixo do sétimo e acima do sexto nó, deixando-se, por estaca, dois pares de folhas cortadas pela metade. As estacas preparadas foram mantidas imersas em água até o momento de irem para o substrato.

As estacas foram tratadas com IBA, onde aproximadamente $1 \mathrm{~cm}$ da base foi introduzida na formulação de po, nas concentrações de zero, $5000,7000,9000$ e $11000 \mathrm{ppm}$, sendo colocadas em baldes plásticos, contendo areia de rio como substrato e mantidas em condições de ncbulização intermitente.

Foram avaliadas o número de estacas enraizadas, nas três épocas, sendo calculada a percentagem de enraizamento, que sofreu a transfor- 
mação arc sen raiz quadrada $(X / 8)$, onde $X$ significa o número de estacas enraizadas e o número 8 , o total de estacas por repetição em cada tratamento. Utilizou-se o delineamento inteiramente casualizado com 15 tratamentos, repetidos nas três épocas de estiolamento, com três repetições para as estacas de ramos estiolados por 40 e 60 dias e seis repetições para as estacas de ramos não estiolados. Empregou-se 24 estacas para os tratamentos com ramos estiolados e 48 estacas para os tratamentos provenientes de ramos não estiolados.

\section{RESULTADOS E DISCUSSÃO}

Os resultados da variável percentagem de estacas enraizadas são apresentados conforme as três épocas de estiolamento (TABELA 1). As causas da variação quando significativas pelo teste F, foram desdobradas utilizando-se a Análise de Regressão Polinomial. A comparação entre médias, segundo as épocas de estiolamento, foi realizada através do teste de Duncan ao nível de $1 \%$.

Pode-se observarque na época 1 (Maio/ 91) a percentagem de estacas enraizadas foi influenciada pelo IBA apenas em estacas provenientes de ramos que haviam sido estiolados por 60 dias (TABELA 1). $O$ índice de enraizamento foi de $18,3 \%$ na ausência de IBA, decrescendo até a concentração de $11000 \mathrm{ppm}$ (Figura 1). Resultado semelhante foi encontrado em trabalho realizado por RODRIGUES et al. (1987), quando utilizaram estacas capeadas (induzidas) de guaranazeiro (Paullinea cupana) por $\mathbf{4 0}$ dias e sem - emprego de IBA, havendo aumento no enraizamento. DUARTE (1991), por sua vez, observou que o melhor enraizamento de estacas de feijoa, ocorreu na dosagem de 5000 ppm de IBA.

$O$ aumento da percentagem de enraizamento em estacas provenientes de ramos estiolados, na ausência do IBA, pode ser atribuído a um acréscimo na concentração de auxina (IAA) endógena, em função do estiolamento evitar a foto-oxidação das substâncias reguladoras do crescimento. Provavelmente, nas estacas tratadas com IBA, tenha ocorrido grande aumento na concentração de fitohormônios (auxinas endógenas acrescida do IBA). Assim, o decréscimo no percentual de enraizamento das estacas tratadas com IBA, em relação às não tratadas, certamente, deve-se a um efeito fitotóxico do mesmo. O estiolamento provoca elevação da auxina endógena dos tecidos, tornando-se praticamente desnecessária a aplicação artificial do regulador (IBA), para propiciar o enraizamento. IVEI (1979), verificou que a imersão prolongada de estacas de feijoa em 3000 ppm de IBA, ocasionou pequena redução no enraizamento.

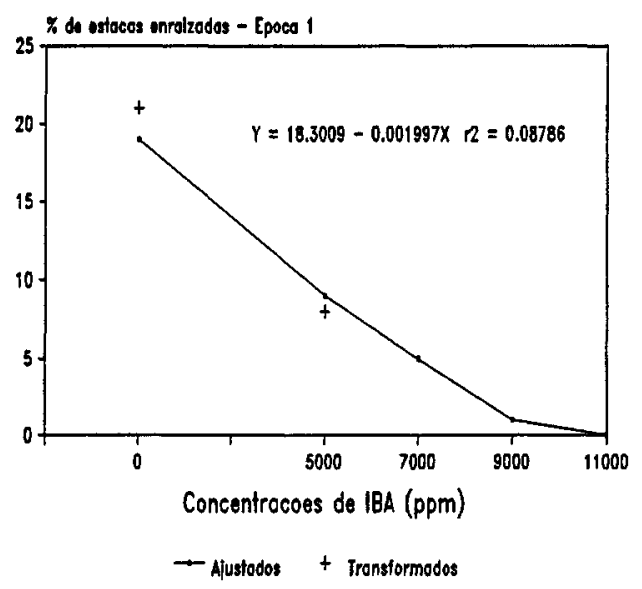

Figura 1 - Percentagem de estacas enraizadas em diferentes concentrações de IBA e 60 dias do fator estiolamento, na época 1.

Entretanto, para as épocas 2 e 3 (Novembro e Fevereiro), observou-se que o enraizamento não foi influenciado significativamente nem pelo IBA, estiolamento e nem pela interação de ambos. Porém, pela observação das médias, verificou-se que em todas as épocas, houve aumento do enraizamento na presença do estiolamento, exceto na época 3 (Fev.), dentro do intervalo de 60 dias de estiolamento (TABELA 1).

Os dados permitiram constatar que 0 melhor intervalo (tempo) de estiolamento foi variável conforme as épocas: na Época 1 (Maio/91), o enraizamento foi melhor em estacas estioladas por 60 dias; nas Épocas 2 e 3 (Novembro/91 e Fevereiro/92), o melhor percentual de enraizamento ocorreu em estacas estioladas por 40 dias (TABELA 1). Tal comportamento, pode ser explicado em função da temperatura e atividade fisiológica da planta. Assim, em maio a temperatura é menor e a planta encontra-se em atividade mais lenta do que em novembro e fevereiro, necessitando de maior tempo de estiolamento (60 dias) para acumular as substâncias promotoras do enraizamento (auxinas, carboidratos, etc.). O contrário ocorre em novembro e fevereiro, sendo necessário menor tempo de estiolamento (40 dias). 
TABELA 1 - Percentagem média de estacas enraizadas em diferentes épocas de estiolamento, intervalos de estiolamento e concentrações de IBA.

\begin{tabular}{ccccccccccc}
\hline \hline \multirow{2}{*}{$\begin{array}{c}\text { AIB } \\
\text { ppm }\end{array}$} & \multicolumn{3}{c}{ MAIO/91 } & \multicolumn{4}{c}{ NOVEMBRO/91 } & \multicolumn{3}{c}{ FEVEREIRO/92 } \\
\cline { 2 - 9 } & Zero & 40 & 60 & Zero & 40 & 60 & Zero & 40 & 60 & Média \\
\hline Zero & 3,5 & 0 & 20,7 & 0 & 16,9 & 6,9 & 18,2 & 19,5 & 6,9 & 10 \\
5000 & 0 & 0 & 6,9 & 8,5 & 6,9 & 10,0 & 9,7 & 16,9 & 0 & 6,5 \\
7000 & 3,5 & 0 & 0 & 6,9 & 6,9 & 0 & 11,9 & 10,0 & 10,0 & 5,5 \\
9000 & 0 & 0 & 0 & 3,5 & 6,9 & 13,8 & 9,5 & 13,8 & 0 & 5,2 \\
11000 & 3,5 & 0 & 0 & 0 & 0 & 0 & 6,9 & 19,5 & 6,9 & 4,1 \\
\hline Média & 2,1 & 0 & 5,5 & 3,8 & 7,5 & 6,1 & 11,0 & 15,9 & 4,8 & \\
\hline \hline
\end{tabular}

Através da análise conjunta dos dados, constatou-se que apenas a época acusou diferença significativa na percentagem de estacas enraizadas (TABELA 2).

TABELA 2 - Percentagem média de estacas enraizadas, em diferentes épocas de estiolamento.

\begin{tabular}{lc}
\hline ÉPOCA & MÉDIAS (\%) \\
& Enraizamento 1\% \\
\hline Fevereiro & $10,86 \mathrm{a}$ \\
Novembro & $5,47 \mathrm{~b}$ \\
Maio & $2,59 \quad \mathrm{~b}$ \\
\hline
\end{tabular}

Médias seguidas por letras distintas diferem significativamente entre sí ao nível de $1 \%$.

Os resultados de enraizamento conforme as épocas, estão de acordo com os encontrados por PIRCHALAJSHVILI \& GORGOSHIDZE (1970); IVEI (1979); KULIEV \& BABAEV (1983) e DUARTE (1991), que mencionam que estacas enraizadas no final do verão e início do outono apresentam melhores resultados do que quando enraizadas em outras épocas.

\section{CONCLUSÕES}

a) $O$ estiolamento parcial de ramos aumentou o número de estacas enraizadas;

Sci. agric., Piracicaba, 52(1):167-171, jan./abr. 1995 b) $O$ ácido indolbutírico nas concentrações utilizadas, não favoreceu o enraizamento de estacas;

c) O melhor intervalo de estiolamento, para o enraizamento de estacas, foi aos 60 dias para a época 1 (Maio) e aos 40 dias para as épocas 2 e 3 (Novembro e Fevereiro).

\section{REFERENCIAS BIBLIOGRÁFICAS}

BABAEV, M.M.; ABBASOVA, K. Vegetative propagation of feijoa. Sadovodstvo, Rockville, n.1, p. 30-31, 1985 .

CACIOPPO, O. La feijoa. Madri: Mundi-Prensa, 1988. 85 .

CASTRO, P.R.C. Mecanismo de ação auxínica. Anais da Escola Superior de Agricultura "Luiz de Queiroz", Piracicaba, v.36, p.621-634, 1979.

DOUD, S.L.; CARLSON, R.F. Effects of estiolation, stem, anatomy and starch reserves on root initiation of layered Malus clones. Journal of the American Society Horticultural Science, Alexandria, v.102, n.4, p.487-491, 1977.

DUARTE, O.R. Efeito da época e do ácido indolbutírico (AIB) no enraizamento de estacas semilenhosas de goiabeira serrana (Feijoa sellowiana, Berg.). Pelotas, 1991, 68p. Dissertaçāo (Mestrado) - Universidade Federal de Pelotas.

FACHINELLO, J.C.; MIELKE, M.S.; NACHTIGAL, J.C. Propagação vegetativa da goiabeira serrana (Feijoa sellowiana, Berg.). Revista Brasileira de Fruticultura, Cruz das Almas, v.14, n.3, p.233-236, 1992. 
GORGOSHIDZE, G.M. The effect of growth stimulators and substrates on the rooting of feijoa cuttings. Subtropicheskie Kul'tury, Rockville, v.6, p.104-108, 1971.

HARTMAN, H.T.; KESTER, D.E. Propagacion de plantas: principios y practicas. México: Continental, 1990. 760p.

IVEI, I.D. Feijoas: selection and propagation. Combined proceedings, Seatle, v.29, p.161-168, 1979.

KULIEV, F.A., BABAEV, M.M. Studies on the vegetative propagation of feijoa. Subtropicheskie Kul'tury, Rockville, v.5, p.127-132, 1983.

MATTOS, J.R. A goiabeira serrana. 2. ed. Porto Alegre: Instituto de Pesquisa de Recursos Naturais Renováveis, 1986, 84p.

MEREDITH, W.C; JOINER, J.N.; BIGGS, R.H. Influences of indole-3-acetic acid and kinetin on rooting and indole metabolism of Feijoa sellowiana. Journal of the American Society Horticultural Science, Alexandria, v.95, n.1, p.49-52, 1970.
PILERI, A.M. La coltura della feijoa in Nouva Zelanda. Rivista di Frutticoltura, Bologna, v.5, p.55-59, 1989.

PIRCHALAJSVILI, S.H., GORGOSHIDZE, G.M. The propagation of feijoa by seeds an cuttings. Subtropicheskie Kul'tury, Rockville, v.3, p.81-89, 1970.

RODRIGUES, J.E.L.F.; LUCCHESI, A.A. Propagação vegetativa do guaranazeiro (Paullinia cupana (Mart.) Ducke) através de estacas induzidas (capeadas) e com ácido indolbutírico. Anais da Escola Superior de Agricultura "Luiz de Queiroz", Piracicaba, v.44, n.1, p.1-20, 1987.

WEAVER, R.J. Reguladores del crescimento de las plantas en la agricultura. México: Trillas, $1976 \mathrm{e}$ 1989, 622p.

Entregue para publicação em 13.12.93

Aceito para publicação em 18.08.94 